\title{
Comparison of Effect of Contact Lenses on Daily Life in Myopia and Myopic Astigmatisma: VF-14 Questionnaire
}

\author{
Umut Duygu Uzunel $^{1 *}$, Bora Yüksel${ }^{1}$, Berna Yuce ${ }^{2}$, Murat Direl $^{1}$, Tuncay Kusbeci ${ }^{1}$ \\ ${ }^{1}$ Izmir Bozyaka Training and Research Hospital, Department of Ophthalmology, Izmir, Turkey \\ ${ }^{2}$ Izmir Tepecik Training and Research Hospital, Department of Ophthalmology, Izmir, Turkey
}

Received: 11 August, 2016; Accepted: 09 October, 2016; Published: 19 October, 2016

*Corresponding author: Umut Duygu Uzunel, Izmir Bozyaka Training and Research Hospital, Department of Ophthalmology, Izmir, Turkey, Tel no: 00.90.232.2900300, Fax no: 00.90.232.2614444; E- mail: druzunel78@yahoo.com

\begin{abstract}
Purpose: To compare the visual functions of individuals with mild to moderate myopia ( $-2.00 \mathrm{D}$ to $-5.00 \mathrm{D})$ and myopic astigmatism $(-1.25 \mathrm{D}$ to $-2.75 \mathrm{D})$ who are wearing contact lenses with those wearing spectacles.
\end{abstract}

Materials and Methods: Eighty participants (40 myopia and 40 myopic astigmatism) who have been followed up at our contact lens unit were included. All participants were using both contact lenses and spectacles. The VF-14 questionnaire was used to compare the impacts of contact lenses wearing versus spectacles on daily life.

Results: In myopic participants, the mean VF-14 scores for spectacles and contact lenses were $89.5 \pm 18.7$ and $96.6 \pm 9.3$ respectively $(\mathrm{p}<0.001)$. There was a statistically significant difference between spectacles and contact lenses in following activities: watching TV, sports involvement, seeing steps/stairs, playing table games and cooking $(\mathrm{p}=0.005, \mathrm{p}<0.001, \mathrm{p}=0.003, \mathrm{p}=0.008, \mathrm{p}<0.001$, respectively, paired t tests).

In participants with myopic astigmatism, mean VF-14 scores for spectacles and contact lenses were $88.7 \pm 21.8$ and $98.3 \pm 6.3$ respectively $(p<0.001)$. Statistically significant difference was found between spectacles and contact lenses for the following activities: doing fine handwork, driving at night, watching TV, sports involvement, seeing steps/stairs, playing table games, cooking and recognizing people at distance $(p=0.001, p=0.039, p=0.001, p<0.001$, $\mathrm{p}=0.031, \mathrm{p}=0.027, \mathrm{p}<0.001, \mathrm{p}=0.023$ respectively, paired tests).

When two groups were compared in terms of all the questions, the VF 14 score was found significantly better in participants wearing contact lenses for the correction of myopic astigmatism during reading small print and doing fine hand work $(\mathrm{p}=0.002$ and $\mathrm{p}=0.005$, respectively; independent sample test).

Conclusions: Wearing contact lenses is more favorable than spectacles in most of daily activities in individuals with mild to moderate myopia and myopic astigmatism. It can improve the quality of life even further in individuals with myopic astigmatism.

Keywords: Contact lens; Myopia; Myopic astigmatism; Spectacles; VF-14 questionnaire

\section{Introduction}

Contact Lenses (CLs) are very common treatment modalities to correct refractive errors especially in young population [1, 2]. Besides the widespread usage of them, some problems like discomfort or infections accompany with the CL wearing. There has been-significant improvement in materials to solve these problems, so as to fit to all users [3].

Many CL wearers can benefit from toric contact lens correction. If all astigmatism of 0.50 Diopters Cylinder (DC) or more were corrected, $61.5 \%$ of wearers would require toric soft contact lens correction. If only astigmatism of $1.00 \mathrm{DC}$ or more was corrected, $34.8 \%$ would require toric correction [4].

An indicator of satisfaction from the use of CLs or spectacles is the quality of life among these patients. There are several questionnaires, evaluating quality of life in patients with refractive errors [5-7]. Visual function 14 (VF-14) is a commonly used vision-related functional questionnaire. ${ }^{8}$ Initially, it was designed to assess vision-related functions in patients undergoing cataract surgery, but it has also been validated for other eye conditions such as glaucoma, retinal, corneal diseases and CLs [9-15]. The VF-14 is easy to administer and to comply with.

The purpose of our study is to evaluate the impact of CLs wear vs. spectacles wear on visual function of young adults with mild to moderate myopia and myopic astigmatism, as they perceive it in their daily life, using the VF-14 questionnaire. We also aimed to evaluate in this study; whether is there a difference between patients with myopia and myopic astigmatism in terms of comfort in daily activities with contact lens wearing.

\section{Methods}

Eighty volunteer participants (40 myopia and 40 myopic astigmatism) who have been followed up at Izmir Bozyaka Training and Research Hospital Contact Lens department were included. Mean Best Corrected Visual Acuity (BCVA) for all patients was $10 / 10$ binocularly. All participants were using both CLs and spectacles. All of them used monthly spheric lens Balafilcon A (Purevision HD, Bosch \&Lomb) and toric lens Balafilcon A (Pure vision 2 for astigmatism, Bosch\& Lomb) CLs. All participants used their CLs mean 10 hours and glasses mean 4 hours in a day. The VF-14 questionnaire was used to compare the impacts of wearing CLs versus spectacles on daily life of young participants. Study participants did not have any other 
ocular disease except myopia and myopic astigmatism and also they didn't use extended wear CLs. The anterior segment was evaluated to ensure that subjects were free of pathology and had no history of previous corneal surgery. The upper age limit was set to 35 years in an attempt to limit age-related tear film changes, as well as to exclude presbyopic subjects. The study was conducted in accordance with the Declaration of Helsinki and approved by the Medical Ethical Committee of Izmir Bozyaka Training and Research Hospital. Informed consent was obtained from all participants.

Following method was used to fit CLs in all participants: Refractive errors were measured with auto refractometer (RKF1; Canon, Tokyo, Japan). Subjective refraction was performed by using a Snellen chart. The lowest myopic and astigmatic values providing patients with best vision were determined. The first trial lens number was determined by substracting the vertex distance value from spectacle correction. After trial fitting CLs were prescribed.

All participants completed the VF-14 questionnaire twice, once for contact lens wear and second for spectacle wear, so as to assess the contact lenses wear vs. spectacles wear impact score on general daily living among the young individuals. It was used as translated in Turkish after following the 'translationback translation' procedure. Participants rate their difficulty in performing daily activities ("No difficulty", "A little difficulty", "A moderate amount of difficulty", "A great deal of difficulty", "Unable to do"). Each question was scored on a scale from 0 (unable to perform an activity at all) to 4 (able to engage in activity fully). The average score was multiplied by 25 to give an overall score ranging from 0 to 100

The SSPS, version 21.0 (IBM, Chicago, IL, USA) statistical package was used for data analyses. Statistical analyses included the chi-square, independent sample, paired t tests and MannWhitney U test. Pearson's correlation analysis was used for correlation between the magnitude of refractive error and VF 14 scores of contact lenses/glasses. A p-value $<0.05$ was considered statistically significant.

\section{Results}

Mean age, sex, mean spherical equivalent and mean time for contact lens wearing of groups are shown on Table 1 and it was seen that both groups have the same features. The BCVA for all patients was 10/10 binocularly. Mean refractive error was $-2.98 \pm 1.18 \mathrm{D}(-2.00 \mathrm{D}$ to $-5.00 \mathrm{D})$ in myopic participants. Mean spherical equivalent was $-3.38 \pm 1.06 \mathrm{D}(-2.00 \mathrm{D}$ to $-5.00 \mathrm{D})$ in participants with myopic astigmatism. Astigmatic range was -1.25 DC to -2.75 DC.

The meanVF-14 scores for spectacles and contact lenses were $89.5 \pm 18.7$ and $96.6 \pm 9.3$ respectively in myopic participants $(\mathrm{p}<$ 0.001). There were significant differences between spectacles and contact lenses for following activities: watching TV, sports involvement, seeing steps/stairs, playing table games and cooking. ( $p=0.005, p<0.001, p=0.003, p=0.008, p<0.001$; respectively, paired $\mathrm{t}$ tests). Whereas, correlation between driving at night and day scores of spectacles and refractive error on VF 14 was significant ( $r=0.418 ; p=0.007, r=0.433 ; p=0.005$, respectively, Pearson correlation analysis). The responses of all participants in CLs and spectacles groups are showed in Table 2.

In participants with myopic astigmatism, the mean VF14 scores for spectacles and contact lenses were $88.7 \pm 21.8$ and $98.3 \pm 6.3$ respectively $(\mathrm{p}<0.001$ ). Statistically significant differences were found between spectacles and contact lenses for the following activities: Doing fine handwork, driving at night, watching TV, sports involvement, seeing steps/stairs, playing table games, cooking and recognizing people at distance ( $\mathrm{p}=0.001, \mathrm{p}=0.039, \mathrm{p}=0.001, \mathrm{p}<0.001, \mathrm{p}=0.031, \mathrm{p}=0.027, \mathrm{p}<$ $0.001, \mathrm{p}=0.023$ respectively; paired t tests) (Table 2).

When the myopic and myopic astigmatism groups were compared in terms of all the questions for contact lenses, the VF-14 scores were found significantly better in participants wearing contact lenses for the correction of myopic astigmatism during reading small print or doing fine handwork ( $\mathrm{p}=0.002$ and $\mathrm{p}=0.005$, respectively; independent sample test) (Table 3).

Individuals were classified in two groups as female $(n=50)$ and male $(n=30)$ to evaluate the difference on comfort in daily activities between contact lens wearers according to gender. The difference between two groups was not significant in terms of age, spherical equivalent and the duration of contact lens wearing ( $\mathrm{p}=0.236, \mathrm{p}=0.516, \mathrm{p}=0.157$, respectively, Mann-Whitney U test). It was noted that females have higher scores in driving at night, watching TV and seeing steps/stairs with contact lens wearing than males (Table 4).

\section{Discussion}

Our investigation showed that CLs are more comfortable than spectacles in daily activities in myopic and myopic astigmatism. Unfortunately, there is no enough study on this topic in literature. Aslam A et al16 found that spectacle wearers were more likely to leave their correction off for daily activities than CL wearers, wearing no vision correction for sports ( $50 \%$ vs. $10 \%$ ), relaxing at home (33\% vs. $12 \%)$, socialising ( $36 \%$ vs. $4 \%$ ) 'out and about' $(26 \%$ vs. $3 \%)$ and work/school (7\% vs. $2 \%)$. Our VF14 questionnaire scores revealed that the use of CLs is more comfortable compare to spectacles for both myopic and myopic

Table 1: Demographic features of myopic and myopic astigmatism groups

\begin{tabular}{|l|l|l|l|}
\hline & $\begin{array}{l}\text { Myopic } \\
\text { groups } \\
\text { (n=40) }\end{array}$ & $\begin{array}{l}\text { Myopic } \\
\text { astigmatic } \\
\text { groups } \\
\text { (n=40) }\end{array}$ & p value \\
\hline Age \pm SD (years) & $24.0 \pm 5.7$ & $23.4 \pm 4.8$ & $0.425^{*}$ \\
\hline Sex (Female:Male) & $13: 27$ & $16: 24$ & $0.485^{* *}$ \\
\hline $\begin{array}{l}\text { Mean spherical equivalant } \pm \\
\text { SD (D) }\end{array}$ & $-2.98 \pm 1.18$ & $-3.38 \pm 1.06$ & $0.110^{*}$ \\
\hline $\begin{array}{l}\text { Mean duration of contact lens } \\
\text { wearing } \pm \text { SD (months) }\end{array}$ & $23.9 \pm 29.5$ & $20.1 \pm 12.6$ & $0.462^{*}$ \\
\hline *Independent sample test ${ }^{* *}$ Chi-square test & & \\
\hline
\end{tabular}


Table 2: Comparison of the Visual Function-14 questionnaire responses for contact lens and spectacle wear in participants with myopia and myopic astigmatism

\begin{tabular}{|c|c|c|c|c|c|c|}
\hline \multirow[b]{2}{*}{ Questions } & \multicolumn{3}{|l|}{ Myopia } & \multicolumn{3}{|c|}{ Myopic astigmatism } \\
\hline & $\begin{array}{l}\text { Mean scores for } \\
\text { CL }\end{array}$ & $\begin{array}{l}\text { Mean scores for } \\
\text { spectacle }\end{array}$ & p value* & $\begin{array}{l}\text { Mean scores for } \\
\text { CL }\end{array}$ & $\begin{array}{l}\text { Mean scores for } \\
\text { spectacle }\end{array}$ & p value* \\
\hline Reading small print & $88.1 \pm 14.9$ & $92.5 \pm 17.1$ & 0.227 & $96.8 \pm 8.4$ & $92.5 \pm 15.2$ & 0.147 \\
\hline Doing fine handwork & $95.6 \pm 9.6$ & $88.7 \pm 19.6$ & 0.070 & $100 \pm 0.0$ & $90.6 \pm 15.7$ & 0.001 \\
\hline Driving at night & $91.3 \pm 13.3$ & $91.2 \pm 18.4$ & 1.000 & $96.3 \pm 9.0$ & $89.4 \pm 21.1$ & 0.039 \\
\hline Reading a newspaper & $97.5 \pm 7.6$ & $93.7 \pm 10.9$ & 0.083 & $96.9 \pm 8.4$ & $94.4 \pm 20.0$ & 0.486 \\
\hline Reading signs & $98.1 \pm 6.7$ & $97.5 \pm 9.6$ & 0.711 & $96.9 \pm 8.4$ & $92.5 \pm 15.2$ & 0.090 \\
\hline Watching TV & $98.1 \pm 6.7$ & $90.0 \pm 14.7$ & 0.005 & $98.1 \pm 6.7$ & $90.0 \pm 14.7$ & 0.001 \\
\hline Sports involvement & $98.7 \pm 7.9$ & $58.1 \pm 25.6$ & $<0.001$ & $100 \pm 0.0$ & $56.3 \pm 35.7$ & $<0.001$ \\
\hline $\begin{array}{l}\text { Writing checks/ completing } \\
\text { forms }\end{array}$ & $97.5 \pm 7.6$ & $96.9 \pm 8.4$ & 0.743 & $98.8 \pm 5.5$ & $98.1 \pm 6.7$ & 0.660 \\
\hline Seeing steps/stairs & $98.1 \pm 6.7$ & $90.6 \pm 12.3$ & 0.003 & $100 \pm 0.0$ & $95.0 \pm 14.1$ & 0.031 \\
\hline Playing table games & $98.7 \pm 5.5$ & $90.6 \pm 12.3$ & 0.008 & $100 \pm 0.0$ & $92.5 \pm 20.6$ & 0.027 \\
\hline Reading large print & $100 \pm 0.0$ & $99.4 \pm 3.9$ & 0.323 & $100 \pm 0.0$ & $100 \pm 0.0$ & 1.000 \\
\hline Cooking & $97.5 \pm 7.6$ & $76.3 \pm 21.1$ & $<0.001$ & $98.1 \pm 6.7$ & $68.8 \pm 21.7$ & $<0.001$ \\
\hline Driving during the day & $96.9 \pm 10.1$ & $92.5 \pm 18.9$ & 0.227 & $96.3 \pm 9.0$ & $92.3 \pm 15.6$ & 0.073 \\
\hline Recognising people at distance & $96.3 \pm 10.7$ & $95.6 \pm 10.2$ & 0.785 & $98.1 \pm 6.7$ & $95.0 \pm 14.1$ & 0.023 \\
\hline
\end{tabular}

Table 3: Comparison of mean scores for contact lens wear in myopia and myopic astigmatism

\begin{tabular}{|l|l|l|l|}
\hline Questions & $\begin{array}{l}\text { Mean scores for } \\
\text { contact lens in } \\
\text { myopic groups }\end{array}$ & $\begin{array}{l}\text { Mean scores } \\
\text { lens in myopia } \\
\text { astigmatic } \\
\text { group }\end{array}$ & p value* \\
\hline Reading small print & $88.1 \pm 14.9$ & $96.8 \pm 8.4$ & $\mathbf{0 . 0 0 2}$ \\
\hline Doing fine handwork & $95.6 \pm 9.6$ & $100 \pm 0.0$ & $\mathbf{0 . 0 0 5}$ \\
\hline Driving at night & $91.3 \pm 13.3$ & $96.3 \pm 9.0$ & 0.053 \\
\hline Reading a newspaper & $97.5 \pm 7.6$ & $96.9 \pm 8.4$ & 0.728 \\
\hline Reading signs & $98.1 \pm 6.7$ & $96.9 \pm 8.4$ & 0.462 \\
\hline Watching TV & $98.1 \pm 6.7$ & $98.1 \pm 6.7$ & 1.000 \\
\hline Sports involvement & $98.7 \pm 7.9$ & $100 \pm 0.0$ & 0.320 \\
\hline $\begin{array}{l}\text { Writing checks/ } \\
\text { completing forms }\end{array}$ & $97.5 \pm 7.6$ & $98.8 \pm 5.5$ & 0.402 \\
\hline Seeing steps/stairs & $98.1 \pm 6.7$ & $100 \pm 0.0$ & 0.079 \\
\hline Playing table games & $98.7 \pm 5.5$ & $100 \pm 0.0$ & 0.156 \\
\hline Reading large print & $100 \pm 0.0$ & $100 \pm 0.0$ & 1.000 \\
\hline Cooking & $97.5 \pm 7.6$ & $98.1 \pm 6.7$ & 0.697 \\
\hline Driving during the day & $96.9 \pm 10.1$ & $96.3 \pm 9.0$ & 0.771 \\
\hline Recognising people at & $96.3 \pm 10.7$ & $98.1 \pm 6.7$ & 0.349 \\
\hline distance & & & \\
\hline Indepen & & & \\
\hline
\end{tabular}

*Independent sample test

Statistically significant $\mathrm{p}$ values were written in bold.

astigmatism, however, this superiority was more prominent in myopic astigmatism (Table 2)

Kanonidouet et al [15] reported that the myopic (mild to moderate) participants were facing more difficulty while they were wearing CLs, while doing fine handwork (i.e. sewing, knitting or carpentry), reading small print/newspapers or driving at night. Contrarily, in our study, no statistically significant difference was found between spectacles and CLs in myopic group while reading small print or doing fine handwork. However, CLs were found significantly superior to spectacles in other daily activities including watching TV, sports involvement, seeing steps/stairs, playing table games or cooking. Wearing CLs for myopic astigmatism was found additionally more comfortable while doing handwork, driving at night and recognizing people at distance. Different results may be a consequence of that all the participants were students in Kanonidou et al's study. Besides, if the difficulty of wearing spectacles during sports or cooking is considered; it is unlikely to get a VF-14 score of 100 .

There is no study evaluating the effect of gender on daily activities in contact lens wearers. Our study reveals that contact lens wearing is more comfortable in females in some daily activities (driving at night, watching TV, seeing steps/stairs).

The first reliable questionnaire exclusively administered on patients with ocular disorders was the VF-14 questionnaire developed by Mangione in 1992.17 Initially, it was designed to assess vision-related functioning in patients undergoing cataract surgery, but it has also been validated for use with other eye conditions such as glaucoma, retinal, corneal diseases and contact lenses.9-15 One of the limitations of our study is the fact that we used the VF-14 questionnaire, although the National Eye Institute Refractive Error Quality of Life-42 (NEI RQL-42) has been also designed for the assessment of patients with refractive error.7 But, VF-14 Questionnaire is an easy to understand and short test.

In conclusion, the essential message of our investigation is that the use of both spectacles and contact lenses provide a 
Table 4: Comparison of mean scores for contact lens wear in female and male

\begin{tabular}{|l|l|l|l|}
\hline Questions & $\begin{array}{l}\text { Mean scores for } \\
\text { contact lens in } \\
\text { females } \\
\text { (n=50) }\end{array}$ & $\begin{array}{l}\text { Mean scores } \\
\text { for contact } \\
\text { lens in males } \\
\text { (n=30) }\end{array}$ & p value* \\
\hline Reading small print & $92.0 \pm 11.8$ & $93.3 \pm 14.6$ & 0.344 \\
\hline Doing fine handwork & $97.5 \pm 17.9$ & $98.3 \pm 6.3$ & 0.612 \\
\hline Driving at night & $96.5 \pm 8.8$ & $89.2 \pm 14.2$ & $\mathbf{0 . 0 0 8}$ \\
\hline Reading a newspaper & $97.0 \pm 8.2$ & $97.5 \pm 7.6$ & 0.785 \\
\hline Reading signs & $97.5 \pm 7.6$ & $97.5 \pm 7.6$ & 1.000 \\
\hline Watching TV & $99.5 \pm 3.5$ & $95.8 \pm 8.5$ & $\mathbf{0 . 0 1 7}$ \\
\hline Sports involvement & $100 \pm 0.0$ & $98.3 \pm 9.1$ & 0.197 \\
\hline Writing checks/ & $98.5 \pm 5.9$ & $97.5 \pm 7.6$ & 0.513 \\
\hline completing forms & $100 \pm 0.0$ & $97.5 \pm 7.6$ & $\mathbf{0 . 0 2 4}$ \\
\hline Seeing steps/stairs & $99.0 \pm 4.9$ & $100 \pm 0.0$ & 0.270 \\
\hline Playing table games & $100 \pm 0.0$ & $100 \pm 0.0$ & 1.000 \\
\hline Reading large print & $97.5 \pm 7.6$ & $98.1 \pm 6.3$ & 0.612 \\
\hline Cooking & & $97.5 \pm 7.6$ & 0.585 \\
\hline Driving during the day & $96.0 \pm 10.5$ & $97.5 \pm 7.6$ & 0.977 \\
\hline $\begin{array}{l}\text { Recognising people at } \\
\text { distance }\end{array}$ & $97.0 \pm 9.6$ & & \\
\hline Mann-Whit & & & \\
\hline
\end{tabular}

*Mann-Whitney U test

Statistically significant $\mathrm{p}$ values were written in bold.

satisfactory visual function for daily activities in young individuals suffering from mild to moderate myopia and myopic astigmatism. However, wearing contact lenses can be more favorable than spectacles in the most of daily activities in individuals with mild to moderate myopia and myopic astigmatism. It can improve the quality of life even further in patients with myopic astigmatism. Results of this study may increase the prescription of toric contact lenses for patients with astigmatism, especially.

\section{References}

1. Riley C, Chalmers RL. Survey of contact lens-wearing habits and attitudes toward methods of refractive correction: 2002 versus 2004 Optom Vis Sci 2005;82(6):555-561.

2. Kanonidou E, Chatziralli IP, Praidou A, Konidaris V. Contact lens usage characteristics among young individuals and their perception regarding future refractive surgery. Graefes Arch Clin Exp Ophthalmol 2011;249(2):307-308. doi: 10.1007/s00417-010-1386-x.

3. Stretton S, Jalbert I, Sweeney DF. Corneal hypoxia secondary to contact lenses: the effect of high Dk lenses. Ophthalmol Clin North Am. 2003;16(3):327-340.
4. Efron N, Nichols JJ, Woods CA, Morgan PB. Trends in US Contact Lens Prescribing 2002 to 2014. Optom Vis Sci. 2015;92(7):758767. doi: 10.1097/OPX.0000000000000623.

5. Jones-Jordan LA, Chitkara M, Coffey B, Jackson JM, Manny RE, Rah $\mathrm{MJ}$, et al. A comparison of spectacle and contact lens wearing times in the ACHIEVE study. Clin Exp Optom. 2010;93(3):157-163. doi: 10.1111/j.1444-0938.2010.00480.x

6. Vitale S, Schein OD, Meinert CL, Steinberg EP. The refractive status and vision profile: a questionnaire to measure vision-related quality of life in persons with refractive error. Ophthalmology. 2000;107(8):15291539.

7. Queirós A, Villa-Collar C, Gutiérrez AR, Jorge J, González- Méijome JM. Quality of life of myopic subjects with different methods of visual correction using the NEI RQL-42 questionnaire. Eye Contact Lens. 2012;38(2):116-121. doi: 10.1097/ICL.0b013e3182480e97.

8. Steinberg EP, Tielsch JM, Schein OD, Javitt JC, Sharkey P, Cassard SD, et al. The VF-14. An index of functional impairment in patients with cataract. Arch Ophthalmol. 1994;112(5):630-638.

9. Hirneiss C, Neubauer AS, Welge- Lussen U, Eibl L, Kampik A. Measuring patient's quality of life in ophthalmology [in German]. Ophthalmologe. 2003;100(12):1091-1097.

10.Sabri K, Knapp CM, Thompson JR, Gottlob I. The VF-14 and psychological impact of amblyopia and strabismus. Invest Ophthalmol Vis Sci. 2006;47(10):4386-4392.

11. Weisinger HS. Assessing the impact of glaucoma using the VF-14. Clin Experiment Ophthalmol. 2009;37(2):241. doi: 10.1111/j.14429071.2009.02011.x

12. Linder M, Chang TS, Scott IU, Hay D, Chambers K, Sibley LM, et al. Validity of the Visual Function Index (VF-14) in patients with retinal disease. Arch Ophthalmol. 1999;117(12):1611-1616.

13. Rohart C, Fajnkuchen F, Nghiem-Buffet S, Abitbol O, Badelon I, Chaine G. Cataract surgery and age-related maculopathy: benefits in terms of visual acuity and quality of life-a prospective study [in French]. J Fr Ophtalmol. 2008;31(6 Pt 1):571-577.

14. Boisjoly H, Gresset J, Charest M, Fontaine N, Brunette I, LeFrançois $\mathrm{M}$, et al. The VF-14 Index of Visual Function in recipients of a corneal graft: a 2-year follow-up study. Am J Ophthalmol. 2002;134(2):166 $-171$.

15. Kanonidou E, ChatziralliIP, Konidaris V, Kanonidou C, Papazisis L. A comparative study of visual function of young myopic adults wearing contact lenses vs. spectacles. Cont Lens Anterior Eye. 2012;35(5):196198. doi: 10.1016/j.clae.2012.07.001.

16. Aslam A, Sulley A, Packe R. Habits of contact lens and spectacle wearers and their attitudes to vision correction. Cont Lens Anterior Eye. 2013;36(Suppl 2):e12-e13. doi: 10.1016/j.clae.2013.08.051.

17. Mangione CM, Phillips RS, Seddon JM, Lawrence MG, Cook EF, Dailey R, et al. Development of the 'Activities of Daily Vision Scale'. A measure of visual functional status. Med Care. 1992;30(12):1111-1126. 